\title{
A novela histórica de Gonçalo: escrita, publicação, recepção
}

\author{
Giuliano Lellis Ito Santos \\ Universidade de São Paulo (São Paulo, Brasil)
}

\begin{abstract}
RESUMO: ESTE ENSAIO SEGUE PRODUÇÃO DA NOVELA HISTÓRIA A TORRE DE D. RAMIRES DE GONÇALO MENDES RAMIRES EM TRÊS ETAPAS: ESCRITA, PUBLICAÇÃO, RECEPÇÃO. COM ISSO, PRETENDE-SE RECONSTRUIR O CENÁRIO DA ÉPOCA PARA ENTENDER COMO O MERCADO EDITORIAL INFORMA A MATÉRIA DA LITERATURA.
\end{abstract}

ABSTRACT: THIS ARTICLE EXAMINES THE PRODUCTION OF THE HISTORICAL NOVEL A TORRE DE D. RAMIRES GONÇALO MENDES RAMIRES IN THREE STEPS: WRITING, PUBLICATION, RECEPTION. WITH THIS, WE INTEND TO RECONSTRUCT THE SCENE OF THE TIME TO UNDERSTAND HOW THE PUBLISHING INDUSTRY TELLS ITS LITERATURE.

PALAVRAS-CHAVE: CRIAÇÃO LITERÁRIA, INDÚSTRIA CULTURAL, ROMANCE HISTÓRICO. KEYWORDS: LITERARY CREATION, CULTURAL INDUSTRY, HISTORICAL ROMANCE. 
m 1897, Eça de Queirós publica, na Revista Moderna, grande parte de $A$ ilustre casa de Ramires. A esta altura, ele já é um escritor experiente, já havia passado por diversos ramos no campo da produção escrita, além de já haver publicado diversos livros, fazia contribuições em diversas revistas e jornais e criara e dirigira uma revista, a Revista de Portugal. Isso dá uma ideia do conhecimento que Eça de Queirós tinha dos meios de produção cultural daquela época. Através de uma contextualização, podemos notar que a encenação da escrita de uma novela dentro de $A$ ilustre casa de Ramires vem a explicitar a relação entre produção escrita e mercado editorial.

O romance inicia-se pela apresentação da atividade do protagonista, que, em seu tempo livre, escreve uma narrativa sobre os feitos um seu tio-avô. Assim, logo nas primeiras linhas, lemos que

desde as quatro horas da tarde, no calor e silêncio do domingo de Junho, o Fidalgo da Torre, em chinelos, com uma quinzena de linho envergada sobre a camisa de chita cor-de-rosa, trabalhava. Gonçalo Mendes Ramires (...) trabalhava numa novela histórica. (QUEIRÓS, 1999, p. 73)

Neste trecho destaca-se a relação entre escrita e trabalho, já que mais de uma vez o narrador afirma que Gonçalo trabalhava. Sobre a novela se pode afirmar que já tinha um título, ao menos no encadeamento narrativo ele já aparece: "A Torre de D. Ramires". Neste título lemos claramente o nome que dá razão à posição política e social de Gonçalo, seu sobrenome, Ramires, que muitas vezes é repetido e evocado para lembrar a "antiguidade da sua raça, mais antiga que o Reino” (QUEIRÓS, 1999, p. 84). Além, é claro, da presença da torre, símbolo da antiguidade da família.

Deste ponto de vista, podemos ressaltar que a novela tem a intenção de resgatar, através de uma narrativa com ranço de romance histórico, a memória do nome familiar. Afinal, Gonçalo cria uma narrativa em que sua raça é "popularizada por uma história de heróica beleza, em que com tanto fulgor ressaltavam a bravura e a soberba de alma dos Ramires” (QUEIRÓS, 1999, p. 84). Neste ponto, temos que a primeira intenção da narrativa é contar a história da família para exaltar a honra da casa heróica.

Ainda sobre a novela, sabemos que o periódico em que se dá a publicação são os "Anais de Literatura e História". Esta revista foi fundada por um amigo 
de Gonçalo, José Lúcio Castanheiro, chamado de Castanheiro Patriotinheiro, que afirma, num dos diálogos com Gonçalo que "Portugal, menino, morre por falta de sentimento nacional!” (QUEIRÓS, 1999, p. 82). O conteúdo dos artigos desta revista pode ser inferido através desta frase, mas, para ficar mais claro, vale destacar que antes do Castanheiro fundar esta revista, ele já havia criado um semanário chamado "A Pátria". Neste periódico, Gonçalo havia publicado uma narrativa de sua autoria, intitulada "D. Guiomar", que teve boa recepção por parte de seu amigo, pois ele afirma que as páginas escritas pelo protagonista, três no total, eram "de óptima cor arcaica! Lembra até $O$ Bobo, O Monge de Cister!" (QUEIRÓS, 1999, p. 79). Neste caso, podemos afirmar que a ideologia destas duas revistas e, provavelmente, a de seu criador, é pautada pelo nacionalismo português. Quanto a isso, é preciso lembrar que a data de publicação de A ilustre casa de Ramires na Revista Moderna é muito próxima ao Ultimatum inglês de 1890, incidente que gerou uma onda de nacionalismo em Portugal. Também se pode destacar que a própria ação do romance parece ser ambientada na mesma época deste acontecimento.

Retomando. Temos um cenário em que um homem do século XIX, de família aristocrática, escreve uma novela sobre um antepassado seu, para ser publicada numa revista de cunho patriótico, da qual um amigo seu era o fundador. Amigo este que já havia publicado uma narrativa de Gonçalo, demonstrando que os seus escritos estavam incluídos no padrão da revista.

Dentro deste cenário, Gonçalo faz uso de um escrito de seu tio Duarte, que

nos seus anos de ociosidade e imaginação, de 1845 a 1850, entre sua carta de bacharel e o seu alvará de delegado, fora poeta e publicara no Bardo, semanário de Guimarães, um poemeto em verso solto, o Castelo de Santa Ireneia” (QUEIRÓS, 1999, p. 85).

Este excerto contrapõe o trabalho do escritor Gonçalo e a ociosidade e a imaginação de seu tio Duarte. Ainda se pode notar que as narrativas são diferentes na própria forma como fica claro nas palavras do protagonista, que acerca da escrita de sua novela, afirma que "na realidade só lhe restava transpor as fórmulas fluidas do Romantismo de 1846 para a sua prosa máscula” (QUEIRÓS, 1999, p. 86). A distinção proveniente desta comparação demonstra a instabilidade do mercado e seu público. Dessa forma, estamos 
diante da lógica econômica, reforçada com a ascensão da burguesia, baseada na mudança contínua, situação observada por Marx e Engels e apresentada da seguinte forma:

todas as relações fixas e enferrujadas, com seu séquito de veneráveis representações e concepções, são dissolvidas; todas as relações novas, posteriormente formadas, envelhecem antes que possam enrijecer-se. Tudo o que está estratificado e em vigor volatiliza-se, todo o sagrado é profanado. (MARX et ENGELS, 1998, p. 11)

Tendo em mente esse sistema volúvel, teríamos no campo da arte a questão da originalidade, noção romântica, que ascende juntamente com a burguesia. Dessa maneira, as formas literárias tendem a seguir a volubilidade do mercado, pois, através da ideia romântica de originalidade, passamos a ter a reinvenção como principal forma de agir dentro do campo literário.

Em Portugal, o poema de cunho histórico teve seu período de forma privilegiada, provavelmente o poemeto do tio Duarte seja desta época, em que

as primeiras levas românticas, leitoras de Camões e D. Branca, de Garrett, ou de A Noite do Castelo e Os ciúmes do Bardo, de Castilho: poemas longos, híbridos, de cariz lírico-narrativo mas tantas vezes de discurso largamente dramatizado, isto é, dispondo de quase todos os recursos de quase todos os géneros, inclusive de um narrador, como qualquer narrativa, pois é de narrativa em verso que trata. (MORNA, 2000, p. 334)

Ao passo que o romance histórico, seguindo as referências presentes em $A$ ilustre casa, tem origem com Walter Scott e passa a ser exercitado em Portugal por Alexandre Herculano, seguindo esta tradição vale destacar Rebelo da Silva, que é algumas vezes apontado como inspiração da novela de Gonçalo, como se pode perceber na citação de um verbete do Dicionário de Eça de Queirós: "as semelhanças entre Ódio Velho não Cansa e A Torre de D. Ramires são tão numerosas que é muito possível que Eça tenha usado a obra de Rebelo da Silva como modelo irónico do romance 'escrito' por Gonçalo” (MATOS, 1993, p. 516).

Desse ponto de vista, temos duas reconstruções. Em primeiro lugar, a transformação do poemeto do tio Duarte na prosa convencionada no final do século XIX. Em segundo lugar, aparece a escritura de um livro "que pretende pos- 
suir todos os tiques de um género que tivera sua época áurea algumas décadas atrás" (MARINHO, 1999, p. 107). Porém, a estrutura do romance de Eça de Queirós desvenda o hibridismo do gênero, sua construção está embasada pela conjugação de diversos discursos. Dessa forma, tendo em mente a observação de Maria de Fátima Marinho de que "A Ilustre Casa Ramires (1900) não pode ser considerado como romance histórico ao mesmo nível de qualquer outro. Nele assistimos a uma desconstrução da concepção que presidia à feitura e ingredientes próprios do género" (MARINHO, 1999, p. 106).

Ao mesmo tempo em que o romance apresenta uma reconstrução do romance histórico na sua estrutura com as diversas narrativas conjugadas, a novela histórica, escrita por Gonçalo, deixa transparecer seus modelos através da pesquisa, que expõe a intenção do escritor, como notamos quando seu amigo, o Castanheiro, elogia a sua narrativa, comparando-a à de Herculano. Dessa maneira, entre os livros dispersos pelo quarto na Torre estão alguns tomos soltos do Panorama e as obras de Walter Scott. Por aí, vemos que o modelo para sua narrativa é o romance histórico tradicional. Neste caso não podemos nos esquecer de Rebelo da Silva, possível referência irônica, pois aparece como a persistência do gênero depois de seu período de grande reconhecimento. Neste caso, não se pode esquecer uma observação de Gonçalo sobre o poemeto de seu tio, em que "a ressurreição do velho Portugal, tão bela no Castelo de Santa Ireneia, não era obra individual do tio Duarte - mas dos Herculanos, dos Rebelos, das Academias, da erudição esparsa" (QUEIRÓS, 1999, p. 86). Neste ponto, notamos que os modelos de Gonçalo e de seu tio são semelhantes, ao menos é isso que esse comentário faz parecer.

O principal modelo de Gonçalo é o poemeto O Castelo de Santa Ireneia, mas em alguns momentos percebemos a utilização de outras fontes na construção da novela, notamos isso na passagem em que surge a afirmação de que ele "adornara a soturna sala afonsina com alfaias tiradas do tio Duarte, de Walter Scott, de narrativas do Panorama” (QUEIRÓS, 1999, p. 129). Ter como modelo o romance de Herculano parece ser um pré-requisito para a inclusão de sua novela na revista. Isso fica mais claro se mostrarmos as opiniões de Castanheiro, depois de ler as alguns trechos da narrativa

planeio imensos cartazes, pregados a cada esquina de cada cidade de Portugal, anunciando em letras de côvado a aparição salvadora dos Anais! E, como ten- 
ciono prometer neles aos povos a sua preciosa novelazinha, desejo que o amigo Gonçalo me informe se ela tem, à moda de 1830, um saboroso subtítulo, como Episódios do Século XII, ou Crónica do Reinado de Afonso II, ou Cenas da Meia Idade Portuguesa... Eu voto pelo subtítulo. Como o subsolo num edifício, o subtítulo num livro alteia e dá solidez. À obra, pois, meu Ramires, com essa imaginação feracíssima”... (QUEIRÓS, 1999, p. 197)

Nesse excerto, notamos que o exemplo para a inclusão do subtítulo é o romantismo de 1830. Em outra observação sobre a novela de Gonçalo, surge, pela voz de André Cavalheiro, um julgamento do criador dos Anais, neste caso ele aponta para a qualidade da narrativa, comparando novamente com o romantismo português "- Lá encontrei também o Castanheiro... Entusiasmado com o teu romance. Parece que nem no Herculano, nem no Rebelo existe nada tão forte, como reconstrução histórica” (QUEIRÓS, 1999, p. 435).

A inspiração romântica do periódico deixa transparecer a ideologia que informa a criação literária de Gonçalo, mesmo que a sua escolha em participar dessa publicação já seja um indício de sua provável concordância com os modelos e conteúdos.

Para esclarecer a familiaridade de Gonçalo com os padrões dos Anais ou não, podemos contrapor dois pensamentos em momentos diferentes do romance. O primeiro ocorre antes da finalização da novela, ainda no segundo capítulo, nela fica patente a utilização, por parte do protagonista, da oportunidade de escrever como um trampolim, uma oportunidade de ser reconhecido:

...os Anais de Literatura e História, com a sua colaboração de professores, de políticos, até de um ministro, o Guerreiro Araújo, esse tocante maçador. Apareceria pois nos Anais com a sua Torre, revelando imaginação e um saber rico. Depois, trepando da Invenção para o terreno mais respeitável da Erudição, daria um estudo (...) sobre as Origens Visigóticas do Direito Público em Portugal... Oh, nada conhecia, é certo, dessas Origens, desses Visigodos.

Como se pode notar a relação de Gonçalo com os Anais de Literatura e História era de interesse pessoal, portanto sua adequação aos padrões do periódico era uma obrigação para concluir seus planos. No segundo pensamento, presente lá pelo meio do romance, no capítulo $\mathrm{V}$, vemos, da mesma forma que na 
passagem anterior, o protagonista expor suas intenções pessoais: "e realmente agora convinha que terminasse essa Torre de D. Ramires antes do afã d'Eleição - para que em janeiro, ao abrir das Cortes, surgisse na Política com o seu velho nome aureolado pela Erudição e pela Arte" (QUEIRÓS, 1999, p. 241).

Nesses dois excertos, notamos que Gonçalo tem certa intenção em ligar sua Torre à Erudição, pois, assim, asseguraria a permanência dos privilégios familiares.

A recepção dos jornais, quando da saída da novela, não é muito diferente das observações do Castanheiro no momento da leitura das provas:

...nos começos de Dezembro, com o primeiro número dos Anais, apareceu a Torre de D. Ramires. E todos os jornais, mesmo os da oposição louvaram “esse estudo magistral (como afirmou $A$ Tarde) que, revelando um erudito e um artista, continuava, com uma arte mais moderna e colorida, a obra de Herculano e de Rebelo, a reconstituição moral e social do velho Portugal heróico". (QUEIRÓS, 1999, p. 443)

Neste ponto, temos que a intenção de produzir uma obra nos moldes do romance histórico, baseado em Herculano e Rebelo da Silva, é atingido. De outra forma, podemos apontar que a indústria cultural do Portugal representado em $A$ ilustre casa de Ramires é um sistema ainda embasado na literatura romântica, já que o meio de divulgação informa a criação literária, exigindo do escritor o conhecimento desta tradição literária para que ele possa recriar a narrativa. Na outra ponta, o leitor, representado pelos jornais e pelo diretor da revista, aprova, não a qualidade do projeto, mas sua adequação.

Desse modo, lembrando uma observação de Adorno e Horkheimer sobre a indústria cultural, "o fato de que suas [da indústria cultural] inovações características não passem de aperfeiçoamentos da produção em massa não é exterior ao sistema" (HORKHEIMER et ADORNO, 1985, p. 127). Teríamos que a representação do processo de criação de Gonçalo apresenta uma encenação de um sistema que ao mesmo tempo em que pauta-se na mudança, como vimos na citação de Marx e Engels, não permite uma mudança na base da estrutura, mas somente na superfície. Assim, um poema ancorado no romantismo plangente transforma-se num romance com fundo histórico-científico, o que vemos neste caso é a transformação da forma superficial em detrimento do conteúdo. 
Por esse ponto de vista, podemos perceber que o mercado que padroniza a matéria literária espera o aprimoramento da forma, mas somente até o ponto em que ela seja identificável facilmente.

\section{Referências bibliográficas}

HOKHEIMER, Max et ADORNO, Theodor W. A indústria cultural: o esclarecimento como mistificação das massas. In HOKHEIMER, Max et ADORNO, Theodor W. Dialética do esclarecimento: fragmentos filosóficos. Trad. Guido Antonio de Almeida. Rio de Janeiro: Jorge Zahar Ed., 1985, p. 113-156.

MARINHO, Maria de Fátima. O romance histórico em Portugal. Lisboa: Campo das Letras, 1999.

MARX, Karl et ENGELS, Friedrich. Manifesto do Partido Comunista. Revista de Estudos Avançados, São Paulo, 12 (34), p. 7-46, set/dez 1998.

MATOS, A. Campos (Org.). Dicionário de Eça de Queiroz: $2^{\mathrm{a}}$ ed. Lisboa: Caminho, 1993.

MORNA, Fátima de Freitas. A ilustre casa de Ramires e a balada romântica. In MATOS, A. Campos. Suplemento ao Dicionário de Eça de Queiroz: Lisboa: Caminho, 2000, p. 332-342.

QUEIRÓS, Eça de. A ilustre casa de Ramires. Lisboa: Imprensa Nacional; Casa da Moeda, 1999.

Recebido em 04 de maio e aprovado em 26 de maio de 2011. 